\title{
Constitutive Expression of a 92-kD Gelatinase (Type V Collagenase) by Rheumatoid Synovial Fibroblasts and Its Induction in Normal Human Fibroblasts by Inflammatory Cytokines
}

Elaine N. Unemori, * Margaret S. Hibbs, ${ }^{*}$ and Edward P. Amento*

*Inflammation, Bone and Connective Tissue Research, Developmental Biology, Genentech, Inc., South San Francisco, California 94080; and ${ }^{\ddagger}$ Rheumatology Division, University of Connecticut School of Medicine,

Newington Veterans Administration Medical Center, Newington, Connecticut 06111

\begin{abstract}
Synovial fibroblasts freshly isolated from the rheumatoid joint are characterized by their marked connective tissue degradative ability. This phenotype includes the ability to secrete large amounts of the matrix-degrading metalloproteinases, collagenase, and stromelysin. We have found that another aspect of this phenotype is the constitutive expression at both protein and mRNA levels of a 92-kD gelatinolytic metalloproteinase, which is not secreted by normal dermal or lung fibroblasts and is immunologically cross-reactive with a type $V$ collagenase expressed by activated macrophages and neutrophils. Expression of this 92-kD metalloproteinase confers upon the fibroblasts the capacity to degrade collagenase- and stromelysin-resistant interstitial elements, such as collagen types IV, $\mathrm{V}$ and $\mathrm{XI}$. In contrast to the 92-kD metalloproteinase, a 68-kD gelatinase (type IV collagenase) was expressed by all fibroblast types studied, indicating that its regulation is distinct from that of the 92-kD gelatinase. To identify what cytokines may be important in the induction of the rheumatoid synovial phenotype, including expression of the 92-kD gelatinase, we exposed normal dermal fibroblasts to a number of cytokines including many known or considered likely to be present in rheumatoid synovial fluid and tissue. Although IL-1 $\beta$, tumor necrosis factor- $\alpha$, lymphotoxin, platelet-derived growth factor, and basic fibroblast growth factor were capable of stimulating fibroblasts to secrete collagenase, only tumor necrosis factor- $\alpha$, lymphotoxin, and IL-1 $\beta$ were able to induce expression of the $92-\mathrm{kD}$ gelatinase, demonstrating discordant regulation of the two metalloproteinases. Expression of the 68-kD gelatinase was independent of that of the 92-kD gelatinase, as demonstrated at the protein and mRNA levels. Late passage rheumatoid synovial fibroblasts, which no longer constitutively expressed the 92-kD gelatinase, displayed an accentuated response to $I L-1 \beta$ when compared to normal dermal fibroblasts. Thus, in addition to IL-1 $\beta$, tumor necrosis factor- $\alpha$ or lymphotoxin may contribute to the expression of a specific rheumatoid synovial phenotype in vivo
\end{abstract}

This work has previously been presented as an abstract in 1990 (Arthritis Rheum. 33:S150).

Address correspondence to Dr. Elaine N. Unemori, Department of Developmental Biology, Genentech, Inc., 460 Pt. San Bruno Blvd., South San Francisco, CA 94080.

Received for publication 31 October 1989 and in revised form 23 May 1991.

J. Clin. Invest.

(c) The American Society for Clinical Investigation, Inc.

$0021-9738 / 91 / 11 / 1656 / 07 \quad \$ 2.00$

Volume 88, November 1991, 1656-1662 that is associated with progressive matrix destruction. (J. Clin. Invest. 1991. 88:1656-1662.) Key words: metalloproteinase • extracellular matrix degradation • rheumatoid arthritis

\section{Introduction}

In rheumatoid arthritis, inflammatory cells such as activated macrophages and $T$ cells interact with resident stromal cells of cartilage and bone resulting in destruction of the extracellular matrix and joint dysfunction (1). These interactions are probably mediated in large part by cytokines secreted by activated macrophages (2), such as IL-1 $\beta$ (3), tumor necrosis factor $(\text { TNF- } \alpha)^{1}(4,5)$, and transforming growth factor- $\alpha$ (TGF- $\left.\alpha\right)(6)$, and lymphocyte products, such as interferon-gamma (IFN- $\gamma$ ) (7) and lymphotoxin (LT or TNF- $\beta$ ) (8). Among these cytokines, some may be directly responsible for causing the normally quiescent synovial fibroblast to attain an aggressive matrix-degrading phenotype, which includes the ability to secrete large amounts of the metalloproteinases, procollagenase (9), and prostromelysin (10). The secretion of these enzymes confers upon the fibroblasts the capability of degrading many constituents of the extracellular matrix, including interstitial collagen types I-III (11), fibronectin, laminin, and proteoglycan (12). Other enzymes probably contribute to the breakdown of cartilage and bone manifested in rheumatoid arthritis, either by accelerating the degradation of these matrix components or by digesting stromelysin (SL)- or collagenase (CL)-resistant matrix elements.

In the present study, we have found that another aspect of the rheumatoid synovial fibroblast phenotype is the constitutive expression of a $92-\mathrm{kD}$ gelatinase (GL) that is not secreted by normal dermal or fetal lung fibroblasts. The $92-\mathrm{kD} \mathrm{GL}$ is immunologically cross-reactive with, and may be identical, to a number of reported gelatinases ranging from 85 to $92 \mathrm{kD}$, which share substrate specificities and are secreted by activated macrophages and neutrophils (13-15). As such, the 92-kD GL is capable of degrading collagen types IV, V, and XI, which are resistant to digestion by $\mathrm{CL}$ and $\mathrm{SL}$, and denatured collagens (gelatin) of many types $(15,16)$. As an approach to understanding what cytokines may play a role in causing the conversion of the synovial fibroblast from benign to destructive in rheumatoid arthritis, we have used the expression of the $92-\mathrm{kD} \mathrm{GL}$ as a marker for the rheumatoid synovial fibroblast phenotype and

1. Abbreviations used in this paper: $\mathrm{CL}$, collagenase; CSF-1, colony stimulating factor- 1 ; bFGF, basic fibroblast growth factor; GL, gelatinase; LH, lactalbumin hydrolysate; LT, lymphotokin; PDGF, plateletderived growth factor; TGF- $\alpha$, transforming growth factor- $\alpha$; TGF- $\beta$, transforming growth factor $-\beta$; TNF- $\alpha$, tumor necrosis factor- $\alpha$. 
have evaluated a number of cytokines for their ability to stimulate expression of the $92-\mathrm{kD}$ GL by normal dermal fibroblasts.

\section{Methods}

Cell culture. Rheumatoid synovial fibroblasts were isolated from freshly dispersed synovium of patients with rheumatoid arthritis, as previously described with minor modification (17). Briefly, the superficial layer of synovia was dissected, minced, and incubated with frequent pipetting for $60-90 \mathrm{~min}$ in $4 \mathrm{mg} / \mathrm{ml}$ clostridial collagenase (Worthington Biochemical Corp., Freehold, NJ) and 0.1\% DNase I (Sigma Chemical Corp., St. Louis, MO) in DME at $37^{\circ} \mathrm{C}$. An equal volume of $0.25 \%$ trypsin was then added for an additional $30 \mathrm{~min}$. Liberated cells were washed twice in 50\% PBS-50\% DME + 15\% FBS and seeded at $10^{6}-10^{7}$ cells $/ 100 \mathrm{~mm}$ tissue culture plate in DME-FBS. Nonadherent cells were removed by vigorous washing at $24 \mathrm{~h}$. Alternatively, when surgical specimens were small, fibroblasts were obtained from explant cultures of $1-2 \mathrm{~mm}^{3}$ pieces of tissue in DME-FBS. In both instances, cells were used after two passages to ensure exclusion of macrophages from the culture (2). Normal human dermal fibroblasts were either obtained from the American Type Culture Collection (Rockville, MD) (CRL1471 or CRL1454) or from explant culture of normal human skin obtained from rhytidectomy. Normal human fetal lung fibroblasts (American Type Culture Collection, WI38) were also used. For experiments, all fibroblasts were used between passages 2-7 and seeded at $6.2 \times 10^{4}$ cells $/ \mathrm{cm}^{2}$ in 48-well plates in DME-FBS for 24-72 $\mathrm{h}$ before washing and replacement in DME in the presence of $0.2 \%$ lactalbumin hydrolysate (Gibco Laboratories, Grand Island, NY) (DME-LH) for cytokine treatment or medium conditioning for 48-72 h. U937 cells, a line of human immature monocytelike cells (18) were cultured in Iscove's Modified Dulbecco's Medium + 10\% FBS and stimulated with LPS $(50 \mu \mathrm{g} / \mathrm{ml})$ and phorbol myristate acetate (PMA) $(50 \mathrm{ng} / \mathrm{ml})$

Reagents. Recombinant human IL-1 $\beta$ (19), TGF- $\alpha$ (20), transforming growth factor- $\beta$ (TGF- $\beta$ ) (21), TNF- $\alpha$ (22), LT (23), and IFN$\gamma(24)$ were cloned, expressed, and purified at Genentech. Recombinant human platelet-derived growth factor (PDGF) was purchased from Amgen Biologicals (Thousand Oaks, CA) and IL-6, colony stimulating factor-1 (CSF-1, monocyte-CSF), and basic fibroblast growth factor (bFGF) were obtained from R \& D Systems Inc. (Minneapolis, MN). 1,10 phenanthroline, PMSF, and pepstatin A were obtained from Sigma and made up as 100-200 mM stock solutions in DMSO.

Zymographic analysis of metalloproteinases. Zymography of secreted proteins by electrophoresis in $10 \%$ SDS-polyacrylamide gels impregnated with $1 \mathrm{mg} / \mathrm{ml}$ type I gelatin from porcine skin (Sigma) was used to demonstrate the presence of gelatinolytic metalloproteinases in conditioned media $(25,26)$. Conditioned culture medium was mixed with Laemmli sample buffer containing $2.5 \%$ SDS without $\beta$-mercaptoethanol and electrophoresed without boiling under nonreducing conditions. After electrophoresis, gels were washed in 2.5\% Triton X-100 for $30 \mathrm{~min}$ to allow proteins to renature. Gels were then immersed overnight in metalloproteinase substrate buffer ( $50 \mathrm{mM}$ Tris, pH 8.0, 2 $\mathrm{mM} \mathrm{CaCl}{ }_{2}$ ) at $37^{\circ} \mathrm{C}$. Gels were then stained with Coomassie blue R250 to reveal zones of lysis within the gelatin matrix. 1,10 phenanthroline ( $2 \mathrm{mM})$, PMSF (1 mM) or pepstatin A (1 mM) was added to the incubation buffer to identify which classes of proteinases were responsible for lysis of the substrate in the gels (27).

Immunoblotting. Conditioned media were electrophoresed in $7 \%$ SDS-polyacrylamide gels and transferred electrophoretically to nitrocellulose by the method of Towbin et al. (28). Filters were stained with a 1:100 dilution of either a rabbit polyclonal antibody, $\mathrm{MH}-1$, prepared against the human neutrophil 92-kD GL (14) or normal rabbit serum overnight at $25^{\circ} \mathrm{C}$. Following extensive washing, alkaline phosphataselinked anti-rabbit antibody (Boehringer Mannheim Corp., Indianapolis, IN) was applied for $30 \mathrm{~min}$, followed by development using nitroblue tetrazolium and bromochloroindoyl phosphate, according to the manufacturer's directions (Promega Biotec, Madison, WI).
Collagenase assay. Collagenase activity in conditioned media was measured in the ${ }^{14} \mathrm{C}$-collagen fibril assay (29) following activation of media with trypsin $(10 \mu \mathrm{g} / \mathrm{ml})$ for $30 \mathrm{~min}$ at $25^{\circ} \mathrm{C} .1 \mathrm{U}$ of collagenase activity hydrolyzes $1 \mu \mathrm{g}$ collagen $/ \mathrm{min}$ at $37^{\circ} \mathrm{C}$. The collagen substrate was obtained by acetylation of purified calf skin collagen (Vitrogen, Collagen Corp., Palo Alto, CA) using $\left[{ }^{14} \mathrm{C}\right]$ acetic anhydride (30).

Northern blot analysis. Total cytoplasmic RNA was isolated from rheumatoid synovial or dermal fibroblasts using RNAzol (Cinna Biotecx, Friendswood, TX), according to manufacturer's instructions. RNA was separated on formamide/formaldehyde agarose gels (31) and transfered to nylon (Genescreen; Dupont Co., Wilmington, DE). A 2.3 $\mathrm{kb}$ Xba I fragment of the 92-kD GL (16) (generous gift of G. Goldberg, Washington University, St. Louis, MO), a $380 \mathrm{bp} \mathrm{Ncol} \mathrm{fragment} \mathrm{of} \mathrm{the}$ 68-kD GL (32) (kindly provided by Dr. E. A. Bauer, Stanford University, Stanford, CA), and two partially overlapping oligonucleotide probes designed according to the published sequence of collagenase (33) were ${ }^{32} \mathrm{P}$ labeled by random priming (Boehringer Mannheim). Blots were hybridized at $42^{\circ} \mathrm{C}$ overnight and washed at $57^{\circ} \mathrm{C}$ in $0.2 \times$ SSC $+1 \%$ SDS for $1 \mathrm{~h}$. To strip blots, nylon membranes were boiled for $3 \mathrm{~min}$ in water.

\section{Results}

Rheumatoid synovial fibroblasts constitutively express a 92-kD $G L$. Rheumatoid synovial fibroblasts were isolated as described in Methods and used after passage 2 when it has been demonstrated that cultures are free of macrophages (2). Rheumatoid synovial fibroblasts derived from four patients, two primary dermal fibroblast lines (CRL 1471 and CRL 1454), and one fetal lung fibroblast line (WI38) were seeded in DME-FBS $48 \mathrm{~h}$ before switching to serumfree DME-LH. Conditioned media were collected at $72 \mathrm{~h}$. Electrophoresis of the conditioned media on gelatin substrate gels demonstrated that, whereas none of the normal fibroblast cultures expressed a 92$\mathrm{kD} \mathrm{GL}$, all four rheumatoid synovial fibroblast cultures did (Fig. $1 A$ ). These observations have now been extended to nine other patients (data not shown). The 92-kD GL was shown to be a metalloproteinase by complete loss of zymographic activity in the presence of 1,10 phenanthroline $(2 \mathrm{mM})$ in the substrate buffer during the $18-\mathrm{h}$ incubation period (Fig. $1 \mathrm{~B}$ ). PMSF (1 mM), a serine proteinase inhibitor, and pepstatin A (1 $\mathrm{mM})$, an acid proteinase inhibitor, had no effect on the ability of the GL to degrade gelatin. A 68-kD GL, which was also 1,10 phenanthroline-inhibitable, was expressed by all fibroblast types studied (Fig. $1 A$ ).

The higher molecular weight GL produced by rheumatoid synovial fibroblasts comigrated with the $92-\mathrm{kD}$ GL secreted by macrophagelike U937 cells stimulated with PMA and LPS (Fig. $1 \mathrm{~A}$ ). To see whether the fibroblast and macrophage GLs were immunologically cross-reactive, immunoblotting studies were done using an antibody, $\mathrm{MH}-1$, which recognized the 92kD GL expressed by activated macrophages and neutrophils (14). A 92-kD band in media conditioned by rheumatoid synovial fibroblasts was recognized by this antibody; no such band was present in media conditioned by normal fibroblasts (Fig. 2). Conditioned medium from stimulated cultures of U937 cells was used as a positive control and indeed a band at $92-\mathrm{kD}$ in $\mathrm{U} 937$ conditioned medium was recognized by this antibody. The $68-\mathrm{kD}$ GL, which migrates as a $72-\mathrm{kD}$ band upon reduction (14), is also recognized by MH-1 and was present in media conditioned by normal dermal fibroblasts, as well as by rheumatoid synovial fibroblasts, consistent with the zymographic results (Fig. 1). This antibody did not react with a protein with an apparent molecular mass of $\sim 70 \mathrm{kD}$ present in U937-con- 


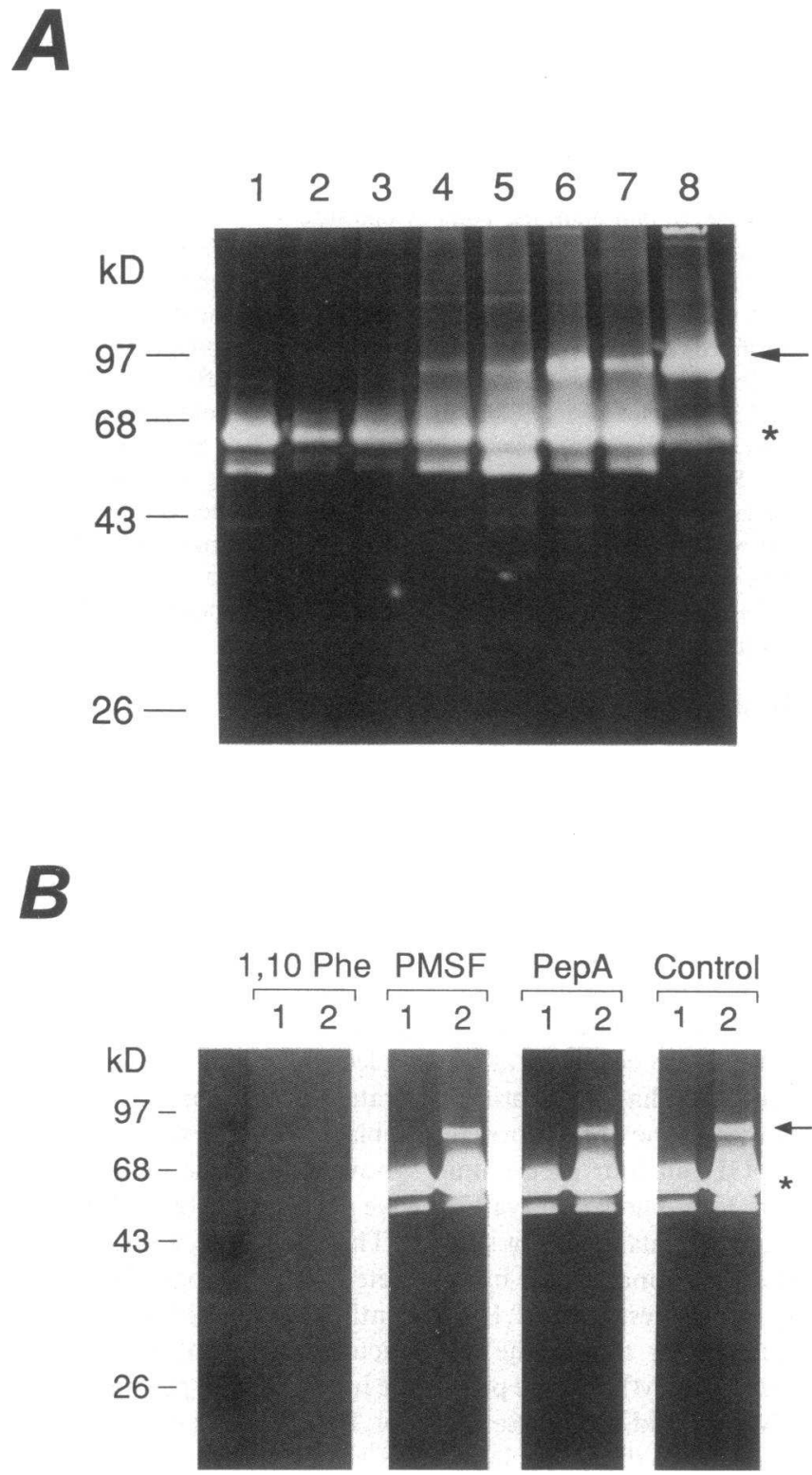

Figure 1. Constitutive expression of a 92-kD GL by rheumatoid synovial fibroblasts and its identification as a metalloproteinase. Fibroblast cultures were grown in DME-LH for $72 \mathrm{~h}$, as described in Methods, and conditioned media were electrophoresed on a gelatin substrate gel. Zones of clearing represent gelatinolytic activity. $(A)$ Three normal fibroblast cultures, CRL 1471 (lane 1), CRL 1454 (lane 2), and WI38 (lane 3) did not express the 92-kD GL (arrow), whereas cultures derived from synovia from four patients with rheumatoid arthritis did (lanes 4-7). U937 cell-conditioned medium was run as a positive control for the $92-\mathrm{kD}$ GL (lane 8 ). A band at $\sim 70 \mathrm{kD}$ in this conditioned medium was contributed by the FBS used to culture these cells (data not shown). A 68-kD GL (asterisk) was prominently represented in conditioned media from all fibroblast cultures. $(B)$ After electrophoresis of conditioned media from normal (lane 1 ) and rheumatoid synovial fibroblast (lane 2) cultures, gelatin substrate gels were incubated in the presence of $2 \mathrm{mM} 1,10$ phenanthroline $(1,10$ Phe), $1 \mathrm{mM}$ PMSF, $1 \mathrm{mM}$ pepstatin A (Pep A), or no inhibitor (Control). All gelatinases, including the 92-kD GL (arrow) and the 68-kD GL (asterisk), were 1,10 phenanthroline-inhibitable but resistant to inhibition by other proteinase inhibitors. Prestained molecular weight markers are in the far left lane.

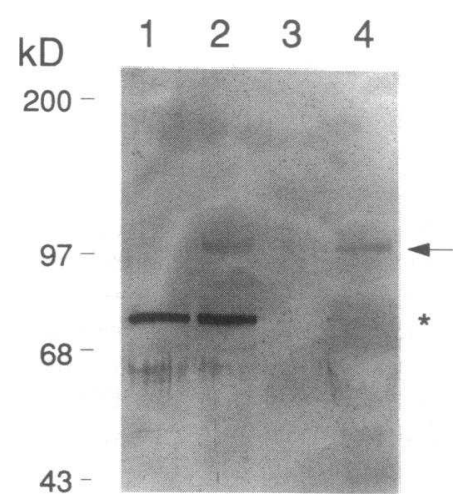

Figure 2. Cross reactivity of the 92-kD GLs from rheumatoid synovial fibroblasts and activated macrophages. Conditioned media from normal dermal fibroblasts (lane 1), rheumatoid synovial fibroblasts (lane 2), DMELH medium alone (lane 3 ), and medium from U937 cells activated with LPS and PMA (lane 4) were electrophoresed, transferred to filters, and subjected to immunoblot analysis using the anti-GL

antibody, MH-1. The antibody identified a band at $92 \mathrm{kD}$ (arrow) in medium from rheumatoid synovial fibroblast and U937 cultures. The 68-kD GL (asterisk) was also recognized in the fibroblast cultures. A similar filter stained with normal rabbit serum failed to resolve either the $92-\mathrm{kD}$ or $68-\mathrm{kD}$ bands (data not shown).

ditioned medium, which displayed some gelatinolytic activity on the substrate gel (Fig. $1 A$ ). This band was found to be a component of the serum (10\% FBS) present in the U937-conditioned medium (data not shown).

Northern blot analysis using cDNA probes for the $92-\mathrm{kD}$ GL and the $68-\mathrm{kD}$ GL was performed on total cytoplasmic RNA extracted from dermal and rheumatoid synovial fibroblasts. Consistent with zymographic and immunoblot results, mRNA for the $92 \mathrm{kD} \mathrm{GL}$ was strongly expressed in rheumatoid synovial fibroblasts but not in dermal fibroblasts (Fig. 3). The 68-kD GL was expressed in both cell types at the mRNA level, consistent with protein results, with expression levels being 1.5-2.0-fold higher in rheumatoid fibroblasts.

Regulation of the 92-kD GL in normal dermal fibroblasts by cytokines. A variety of cytokines have been detected in the synovial fluid and tissue from patients with rheumatoid arthritis (34-39). A number of these were screened for their ability to induce expression of the $92-\mathrm{kD}$ GL in normal dermal fibroblasts. Cytokines were applied to CRL 1471 cells or primary dermal fibroblasts in DME-LH for $\mathbf{4 8} \mathrm{h}$ in roughly equimolar concentrations, including concentrations known to stimulate $\mathrm{CL}$ expression. Conditioned media were then collected and electrophoresed on gelatin substrate gels. TNF- $\alpha(11.8 \mathrm{nM})$, LT (10.5 nM), and, to a lesser extent, IL-1 $\beta(0.4 \mathrm{nM})$ each induced expression of the 92-kD GL (Fig. $4 \mathrm{~A}$ ). At these doses, IL- $1 \beta$, TNF- $\alpha$, and LT caused a roughly equivalent expression of $\mathrm{CL}$ activity $\left(5.7,5.5\right.$, and $4.9 \mathrm{U} / 10^{6}$ cells per $48 \mathrm{~h}$, respectively) (Table I). Concentrations of $0.1 \mathrm{nM} \mathrm{TNF}-\alpha, 0.1 \mathrm{nM} \mathrm{LT}$, and $0.01 \mathrm{nM}$ IL- $1 \beta$ were necessary for maximum induction of the $92-\mathrm{kD}$ GL, with TNF- $\alpha$ inducing the highest levels of expression (Fig. $4 \mathrm{~B}$ ). Treatment with PDGF (3.3 nM) or bFGF ( $5.6 \mathrm{nM}$ ) both increased CL activity ( 2.37 and $3.62 \mathrm{U} / 10^{6}$ cells per $48 \mathrm{~h}$, respectively) but no stimulation in levels of the $92-\mathrm{kD}$ GL was detected (Table I). IL-6, TGF- $\alpha$, CSF-1, TGF- $\beta$, and IFN- $\gamma$ failed to induce either $C L$ activity or expression of the 92-kD GL (Table I, Fig. $3 A$ ). Expression patterns of the 92-kD GL, the $68-\mathrm{kD} \mathrm{GL}$, and CL in response to IL- $1 \beta$, TNF- $\alpha$, and LT were also examined by Northern blot analysis (Fig. 3). mRNA for the $92-\mathrm{kD}$ GL was inducible by $0.1 \mathrm{nM}$ TNF- $\alpha$ and LT, but weakly compared to constitutive levels present in rheumatoid synovial fibroblasts. The $68-\mathrm{kD}$ GL was inducible in a 

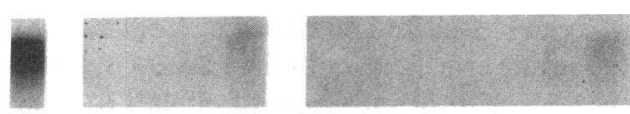

$92 \mathrm{kD} \mathrm{GL}$
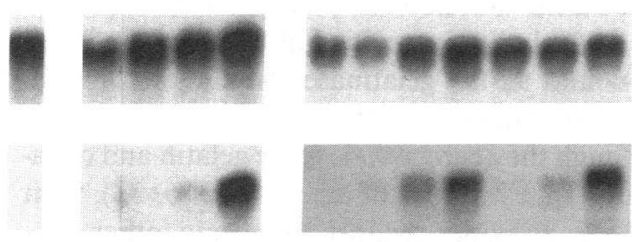

68 kD GL

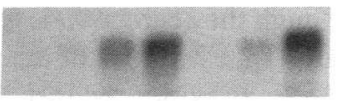

CL
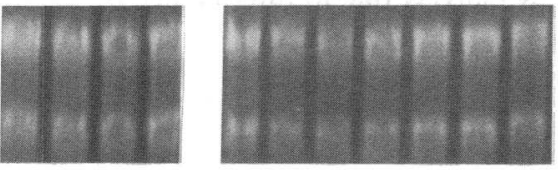

$28 \mathrm{~S}$

$18 S$

$$
\text { R } \frac{0 \stackrel{\overline{0}}{\circ} \overline{0}}{0} \overline{0}
$$

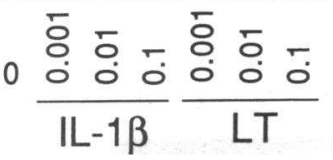

Figure 3. Northern analysis of metalloproteinase expression in rheumatoid synovial and normal dermal fibroblasts. Normal fibroblasts were untreated $(\mathrm{O})$ or treated with $0.001-0.1 \mathrm{nM} \mathrm{IL}-1 \beta$, TNF- $\alpha$, or LT for $48 \mathrm{~h}$ before RNA extraction. RNA was harvested from normal fibroblasts or rheumatoid synovial fibroblasts $(R)$ and resolved on formamide/formaldehyde gels, as described in Methods. Blots were probed sequentially with a 92-kD GL cDNA (16), a 68-kD GL cDNA (32), and two oligonucleotides designed according to the published sequence of CL (33). Intensity of the $18 S$ and $28 S$ RNA staining by ethidium bromide is shown for comparison of total RNA loaded per lane.

dose-responsive manner by IL- $1 \beta$ and TNF- $\alpha$, consistent with zymographic results (Fig. $4 \mathrm{~B}$ ). In the dose range tested, $L T$ had no effect on expression of the 68-kD GL. CL mRNA was stimulated in a dose-dependent manner by all three cytokines.

$I L-1 \beta, T N F-\alpha$, and $L T$ reinduce expression of the 92-kD GL by late passage rheumatoid synovial fibroblasts. The expression of the 92-kD GL by rheumatoid synovial fibroblasts decreased with passage in culture (Fig. $5 A$ ). In contrast, the expression of the 68-kD GL did not decrease with time and in fact was increased in cultures of higher passage number. Fibroblasts carried in culture until the 92-kD GL was no longer expressed were treated with IL1- $\beta$, TNF- $\alpha$, or LT at doses shown to stimulate expression of the $92-\mathrm{kD}$ GL in normal dermal fibroblasts (Fig. $5 \mathrm{~B}$ ). All three cytokines did reinduce expression of the 92-kD GL, with concentrations of $0.01 \mathrm{nM}$ TNF- $\alpha, 0.01 \mathrm{nM}$ LT, and $0.001 \mathrm{nM}$ IL- $1 \beta$ necessary for maximum stimulation. In comparison to normal dermal fibroblasts, however, rheumatoid synovial fibroblasts were more sensitive to all cytokines, but particularly to IL- $1 \beta$; maximum expression of the GL occurred at a 10-fold lower cytokine concentration with more GL being expressed at that maximum.

\section{Discussion}

The inflammatory mass of the rheumatoid synovium (pannus) consists of many cell types, including macrophages, lymphocytes, and fibroblasts. The network of interactions among these cells may be associated with the perpetuation of the degenerative process and the eventual destruction of the extracellular matrix in the underlying cartilage and bone. Secreted products of the rheumatoid synovial fibroblast are largely responsible for the degradation of the collagens $(9,10)$, including types I-III, $\mathrm{V}$, and $\mathrm{XI}$, which are present in the nonmineralized matrix. Interstitial collagenase (EC 3.4.23.6) initiates the degradation
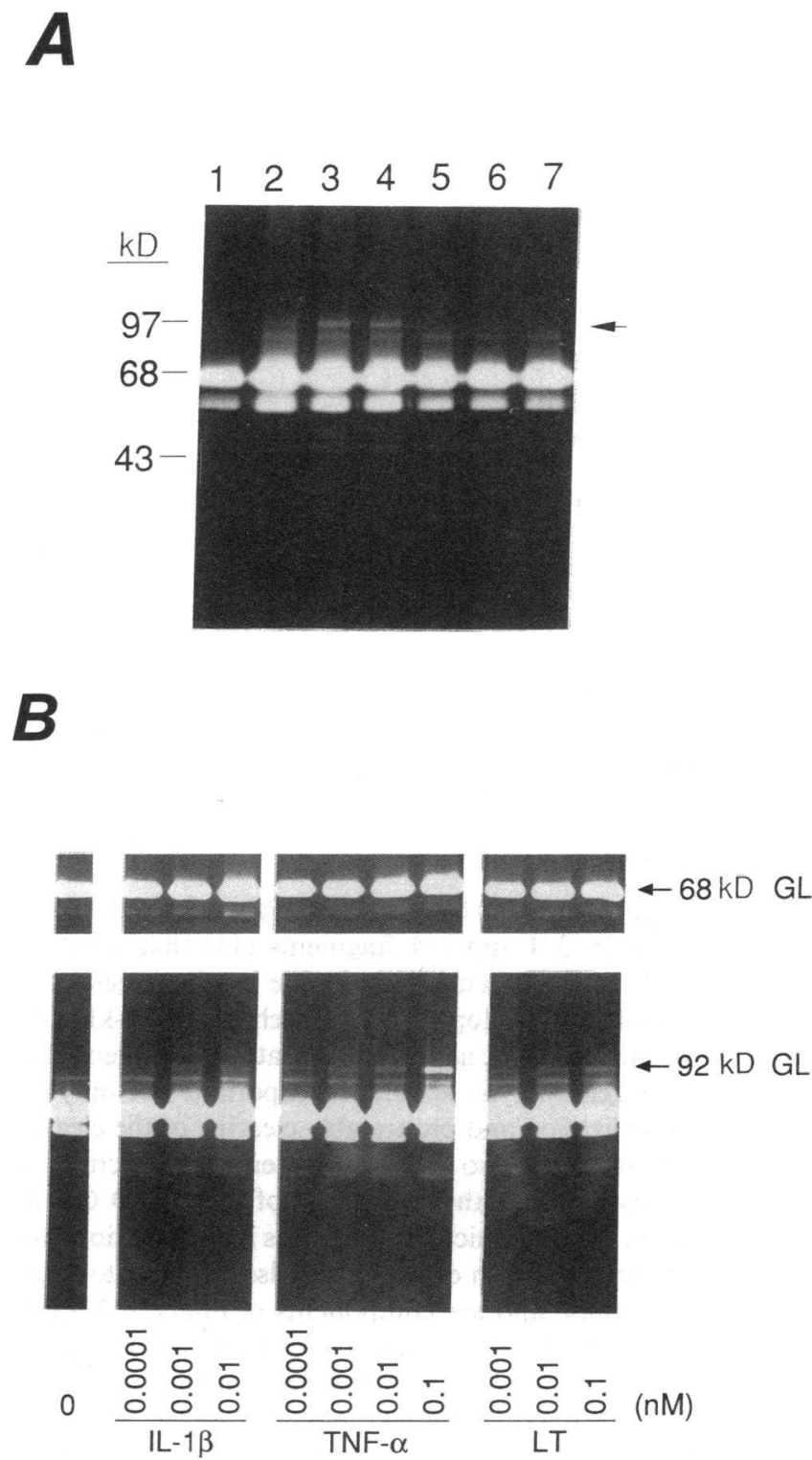

Figure 4. Induction of the $92-\mathrm{kD}$ GL in normal dermal fibroblasts by cytokines. $(A)$ Normal dermal fibroblasts were cultured without addition (lane 1$)$ or with IL-1 $\beta(0.4 \mathrm{nM}$, lane 2$)$, TNF- $\alpha(11.8 \mathrm{nM}$, lane 3$)$, LT (10.5 nM, lane 4), IL-6 (16.6 nM, lane 5), TGF- $\alpha$ (20 nM, lane 6), and CSF-1 (3.7 nM, lane 7) for $48 \mathrm{~h}$. Substrate gel analysis of the conditioned media showed that TNF- $\alpha$, LT and, to a lesser extent, IL-1 $\beta$ induced expression of the $92-\mathrm{kD}$ GL (arrow). (B) Normal dermal fibroblasts were treated with IL- $1 \beta$, TNF- $\alpha$, or LT at $0.0001-0.1$ $\mathrm{nM}$ to determine concentrations necessary for maximum induction of the 92-kD GL (arrow). The cytokine dose-response up to and including the dose-causing maximum induction is shown. Conditioned media were also diluted 1:20 and electrophoresed on a separate zymogram, shown in the panel above, to allow resolution of changes in the levels of the 68-kD GL secreted by fibroblasts following stimulation. 
Table I. Induction of the 92-kD GL and CL in Normal Dermal Fibroblasts by Cytokines

\begin{tabular}{lccc}
\hline Cytokine & Conc & $92-$ kD GL & CL \\
\hline & $n M$ & & $U / m l$ \\
None & & - & 0.57 \\
IL-1 $\beta$ & 0.4 & \pm & 5.70 \\
& 4.0 & \pm & ND \\
TNF- $\alpha$ & 1.2 & + & ND \\
& 11.8 & + & 5.50 \\
LT & 1.1 & + & ND \\
& 10.5 & + & 4.90 \\
PDGF & 0.3 & - & 0.07 \\
& 3.3 & - & 2.37 \\
bFGF & 0.6 & - & 1.42 \\
& 5.6 & - & 3.62 \\
TGF- $\alpha$ & 20.0 & - & ND \\
CSF-1 & 3.7 & - & 0.14 \\
TGF- $\beta$ & 0.4 & - & 0.24 \\
IFN- $\gamma$ & $100 \mathrm{U} / \mathrm{ml}$ & - & 0.0 \\
IL-6 & 16.6 & & 0.16 \\
& & & \\
\hline
\end{tabular}

Normal dermal fibroblasts grown at $6 \times 10^{4}$ cells $/ \mathrm{cm}^{2}$ were treated 48 $\mathrm{h}$ after plating with cytokines at the indicated concentrations. The presence of the $92-\mathrm{kD} \mathrm{GL}$ in $48 \mathrm{~h}$-conditioned medium was monitored by substrate gel analysis, as described in Methods. Total collagenolytic activity in the conditioned media was quantified by ${ }^{14} \mathrm{C}$ collagen fibril assay. ND, not done.

of collagen types I-III (10) by cleaving at a site within the triple helix resulting in $3 / 4$ and $1 / 4$ fragments (11) that denature spontaneously at body temperature. The resultant gelatin is degraded by other metalloproteinases such as the $92-\mathrm{kD} \mathrm{GL}$, which have a high specific activity for denatured collagens (14$16,40)$. This gelatinolytic activity is important not only for efficient solubilization and presumably clearing of the cleaved collagens but its action also appears to potentiate the activity of collagenase itself (13). Other substrates of the $92-\mathrm{kD}$ GL include collagen type $\mathrm{V}$, which is ubiquitous in distribution, and type XI, of cartilage, both of which are also resistant to digestion by collagenase and are components of interstitial fibrils. Type IV collagen, also impervious to collagenase degradation, is cleaved by the $92-\mathrm{kD}$ GL (16). The constitutive expression of the $92-\mathrm{kD}$ GL by the rheumatoid synovial fibroblast, therefore, is consistent with the matrix-degrading phenotype of these cells.

We have demonstrated expression of the 92-kD GL by rheumatoid synovial fibroblasts by three criteria: $(a)$ gelatinolytic activity at the appropriate size by gelatin zymography; $(b)$ immunologic cross-reactivity with a U937 cell line-expressed 92-kD GL; and (c) presence of the mRNA for 92-kD GL as detected by Northern blot analysis. We were unable to demonstrate an increase in total gelatinolytic or type $\mathrm{V}$ collagenolytic activity expressed by the rheumatoid synovial fibroblasts, however, due to interference by the $68-\mathrm{kD}$ GL. This $68-\mathrm{kD}$ gelatinolytic metalloproteinase, which migrates at $72 \mathrm{kD}$ after reduction, is also strongly expressed by rheumatoid synovial fibroblasts. Unlike the 92-kD GL, however, it is also prominent among the metalloproteinases expressed by normal fibroblasts.
This GL, which has been cloned and described by Collier et al. (32), shares some substrate specificity with the 92-kD GL (16), although the full complement of substrates of either GL, but particularly of the 92-kD GL, however, has yet to be explored. Because of this, the relative intensities of the zones of lysis created by the $68-$ and $92-\mathrm{kD}$ gelatinases on the gelatin substrate gel may be misleading in terms of their physiological significance. Although they can both degrade gelatin and collagen types IV and V in a number of assays $(14,16,38)$, their comparative specific activities against these and other substrates are unknown largely due to interference by the inhibi-
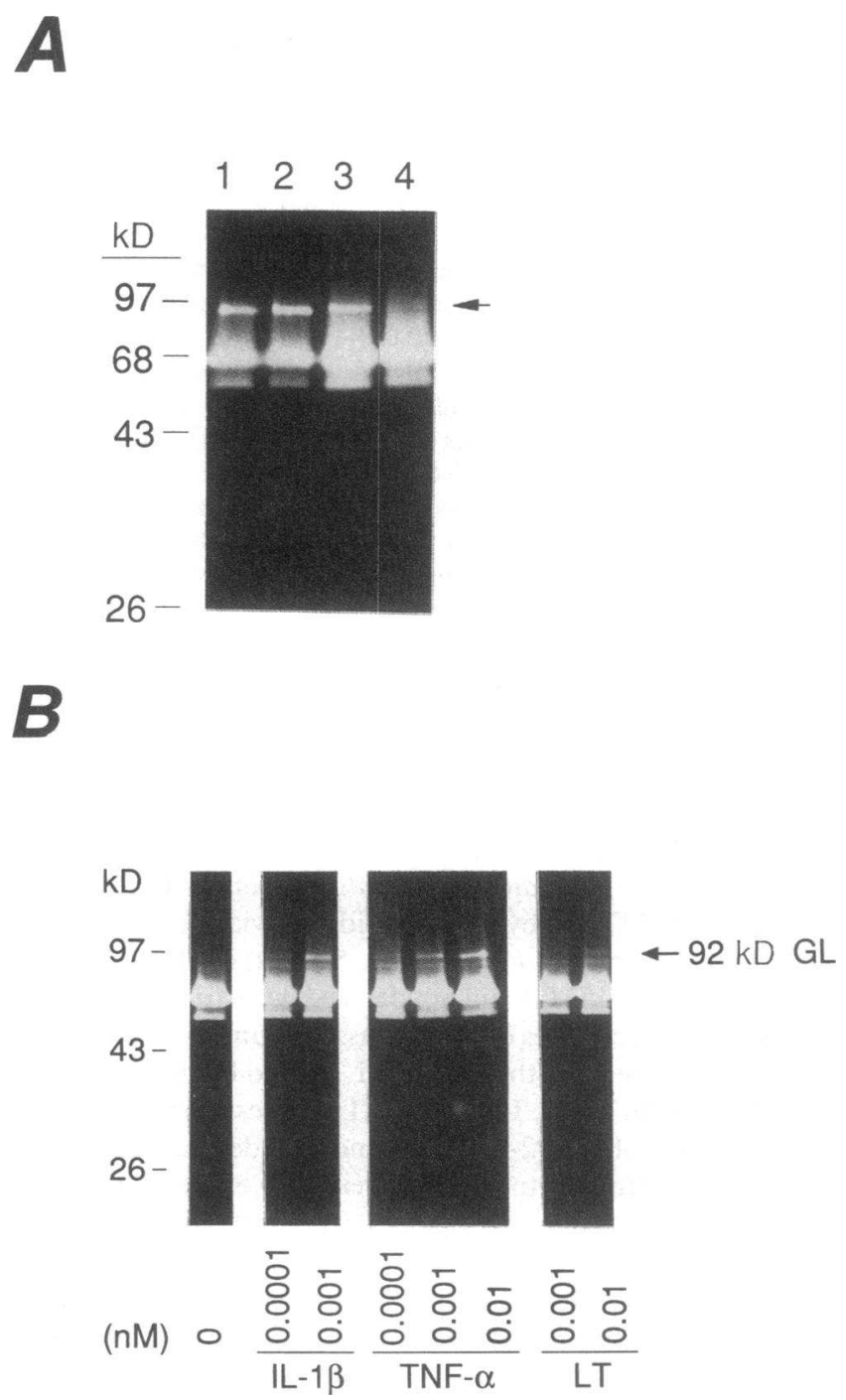

Figure 5. Attenuation and reinduction of $92-\mathrm{kD}$ GL expression by rheumatoid synovial fibroblasts upon incubation with IL- $1 \beta$, TNF- $\alpha$, and LT. $(A)$ Rheumatoid synovial fibroblasts were passaged in culture for eight generations and expression of the 92-kD GL (arrow) was monitored by gelatin gel analysis. The gelatinase was expressed by the synovial fibroblasts at passages 2 (lane 1 ), 4 (lane 2), and 5 (lane 3 ), but had attenuated significantly by passage 8 (lane 4 ). (B) High passage number rheumatoid synovial fibroblasts were stimulated with $0.0001-0.1 \mathrm{nM}$ IL-1 $\beta$, TNF- $\alpha$, or LT for $48 \mathrm{~h}$. The dose-response up to and including the dose-causing maximum induction of the $92-\mathrm{kD}$ GL is shown. 
tor, tissue inhibitor of metalloproteinases, present in these assays. Importantly, how their activities overlap in the context of matrix degradation in vivo remains undetermined. What is clear, however, as we and others $(14,15,32)$ have shown, is that the regulation of the two metalloproteinases is distinct. Expression of the $68-\mathrm{kD}$ gelatinase appears to be tightly regulated in some epithelial cells (32) but in fibroblasts, it is secreted in a ubiquitous manner. This suggests that the roles of the 68- and 92-kD gelatinases in matrix turnover may differ in different cell types and that in fibroblasts, the expression of the $92-\mathrm{kD}$ GL under conditions of inflammation may serve a function unique to this metalloproteinase.

The secretion of the $92-\mathrm{kD}$ GL by freshly isolated rheumatoid synovial fibroblasts may also offer an insight as to the cytokine(s) that originally triggered the matrix degrading phenotype in these fibroblasts in vivo. Although many cytokines have been detected in rheumatoid synovial fluid and tissue (34-39), those that induce the matrix-degradative phenotype in fibroblasts may be few in number. Candidate cytokines include products of activated macrophages, such as IL- $1 \beta$ (34, 35 ), CSF-1 (39), and TNF- $\alpha$ (36), and lymphocyte products, such as LT (41) and IFN- $\gamma(42)$. These cytokines and others were tested on normal dermal fibroblasts and screened for their ability to induce two aspects of the rheumatoid synovial phenotype, namely expression of CL and the 92-kD GL. TGF- $\beta$, which is detected in synovial rheumatoid synovial effusions (38), IFN- $\gamma$, which is presumed to be present in synovial tissue (42), IL-6, which is produced by rheumatoid synovium (37), and TGF- $\alpha$, which is expressed by activated macrophages (6), did not induce expression of either metalloproteinase. A number of cytokines, namely IL- $1 \beta$, TNF- $\alpha$, LT, PDGF, and bFGF, did stimulate $C L$ expression, consistent with previous reports $(3,5,43,44)$. Of all of the cytokines tested, only three of them, TNF- $\alpha, \mathrm{LT}$, and IL- $1 \beta$, stimulated expression of the $92-\mathrm{kD} \mathrm{GL}$ by normal dermal fibroblasts, with TNF- $\alpha$ being the most potent inducer. However, the maximum level of expression inducible by these cytokines was less than that seen produced by rheumatoid fibroblasts constitutively, suggesting that a more complex induction pathway has led to expression of the $92-\mathrm{kD}$ GL in these cells. Treatment of normal fibroblasts with IL- $1 \beta$, TNF- $\alpha$, and LT also demonstrated that expression of the 92$\mathrm{kD} \mathrm{GL}$, the $68-\mathrm{kD} \mathrm{GL}$, and $\mathrm{CL}$ were independently regulated by these cytokines. Although the relative levels of the $92-\mathrm{kD}$ GL mRNA in induced normal fibroblasts are too low to make judgments about dose responsiveness by Northern analysis, the high specific activity of this gelatinase for the gelatin substrate has allowed evaluation of its inducibility in normal fibroblasts by zymography. These results also demonstrate independent regulation of the three metalloproteinases by the inflammatory cytokines.

The expression of the $92-\mathrm{kD}$ GL by rheumatoid synovial fibroblasts decreases with passage in culture. Passage number can be as high as 8 before its expression does decrease, further demonstrating that macrophages are not the source of this metalloproteinase in our cultures. Rheumatoid synovial fibroblasts that were passaged until they lost the induced phenotype were also stimulated to reexpress the $92-\mathrm{kD}$ GL by IL-1 $\beta$, TNF$\alpha$, and LT. Compared to normal fibroblasts, they showed an increased sensitivity to all three cytokines, but particularly to IL- $1 \beta$, consistent with the increased $C L$ and $\mathrm{PGE}_{2}$ responsiveness of these cells to this cytokine. This is perhaps due to some presensitization acquired by exposure to the cytokine milieu in vivo.

IL- $1 \beta$ has long been considered a primary candidate as at least one of the cytokines responsible for stimulation in vivo of synovial fibroblasts in rheumatoid arthritis. The evidence for this includes its ability to stimulate $\mathrm{CL}$ and $\mathrm{PGE}_{2}$ expression (3, 45 ), its role as a mitogen for fibroblasts (46), its presence in synovial fluid (35), and its production by freshly isolated (macrophage-inclusive) synovial tissue (34). Many of these features are applicable to TNF- $\alpha$ and LT, which share the same cellular receptor (47), and stimulate biological activities similar to IL$1 \beta(41,44)$. They stimulate $\mathrm{PGE}_{2}$ and $C L$ production by rheumatoid synovial fibroblasts, although they are less potent than IL- $1 \beta$ in doing so (44). Transcripts for TNF- $\alpha$, as well as for IL- $1 \beta$, have been detected in synovial tissue (48).

In summary, freshly isolated rheumatoid synovial fibroblasts constitutively secrete a $92-\mathrm{kD}$ GL that is immunologically cross-reactive with a type $\mathrm{V}$ collagenase secreted by activated macrophages and neutrophils. Its expression may confer upon fibroblasts the enhanced ability to degrade matrix constituents at sites of chronic inflammation, such as that exemplified by rheumatoid arthritis. The ability of TNF- $\alpha$ and LT to induce expression of the 92-kD GL by normal dermal fibroblasts, as well as to stimulate $\mathrm{CL}$ expression and $\mathrm{PGE}_{2}$ production by fibroblasts $(5,44)$, suggests a role for these cytokines, in addition to IL- $1 \beta$, in potentiating the matrix degradative phenotype of rheumatoid synovial fibroblasts. The expression of the 92$\mathrm{kD} \mathrm{GL}$ was regulated independently of the $68-\mathrm{kD} \mathrm{GL}$ and $\mathrm{CL}$.

\section{Acknowledgments}

We thank Evelyn Berry for her assistance with preparation of the manuscript.

Margaret S. Hibbs is the recipient of funds from the Veterans Administration.

\section{References}

1. Krane, S. M., E. P. Amento, M. B. Goldring, S. R. Goldring, M. L. Stephenson, B. Polla, S. Arai, A. K. Bhan, and J. T. Kurnick. 1986. Cellular interaction and matrix destruction during inflammatory processes within the joints. In Articular Cartilage Biochemistry. K. Kuettner, R. Schleyerbach, and V. C. Hascall, editors. Raven Press, Inc., New York. 413-422.

2. Dayer, J.-M., J. H. Passwell, E. E. Schneeberger, and S. M. Krane. 1980. Interactions among rheumatoid synovial cells and monocyte-macrophages: production of collagenase-stimulating factor by human monocytes exposed to concanavalin A or immunoglobulin Fc fragments. J. Immunol. 124:1712-1720.

3. Dayer, J. -M., B. de Rochemonteix, B. Burrus, S. Demczuk, and C. A. Dinarello. 1986. Human recombinant interleukin 1 stimulates collagenase and prostaglandin E2 production by human synovial cells. J. Clin. Invest. 77:645648.

4. Buetler, B., D. Greenwald, J. D. Hulmes, M. Chang, Y.-C. E. Pan, J. Mathison, R. Ulevitch, and A. Cerami. 1985. Identity of tumor necrosis factor and the macrophage-secreted factor, cachectin. Nature (Lond.). 316:552-554.

5. Dayer, J.-M., B. Beutler, and A. Cerami. 1985. Cachectin/tumor necrosis factor stimulates collagenase and prostaglandin E2 production by human synovial cells and dermal fibroblasts. J. Exp. Med. 162:2163-2168.

6. Rappolee, D. A., D. Mark, M. J. Banda, and Z. Werb. 1988. Wound macrophages express TGF- $\alpha$ and other growth factors in vivo: analysis by mRNA phenotyping. Science (Wash. DC). 241:708-711.

7. Unanue, E. R., D. I. Beller, C. Y. Lu, and P. M. Allen. 1984. Antigen presentation: comments on its regulation and mechanism. J. Immunol. 132:1-5.

8. Aggarwal, B. B., B. Moffatt, and R. N. Harkins. 1984. Human lymphotoxin. Production by a lymphoblastoid cell line, purification, and initial characterization. J. Biol. Chem. 259:686-691.

9. Dayer, J.-M., S. M. Krane, R. G. G. Russell, and D. R. Robinson. 1976. 
Production of collagenase and prostaglandins by isolated adherent rheumatoid synovial cells. Proc. Natl. Acad. Sci. USA. 73:945-949.

10. Okada, Y., H. Nagase, and E. D. Harris, Jr. 1983. A metalloproteinase from human rheumatoid synovial fibroblasts that digests connective tissue matrix components. Purification and characterization. J. Biol. Chem. 261:1424514255.

11. Gross, J., and Y. Nagai. 1965. Specific degradation of the collagen molecule by tadpole collagenolytic enzyme. Proc. Natl. Acad. Sci. USA. 54:11971204.

12. Chin, J. R., G. Murphy, and Z. Werb. 1985. Stromelysin, a connective tissue-degrading metalloendopeptidase secreted by stimulated rabbit synovial fibroblasts in parallel with collagenase. J. Biol. Chem. 260:12367-12376.

13. Murphy, G., J. J. Reynolds, U. Bretz, and M. Baggiolini. 1982. Partial purification of collagenase and gelatinase from human polymorphonuclear leukocytes. Biochem. J. 203:209-221.

14. Hibbs, M. S., K. A. Hasty, J. M. Seyer, A. H. Kang, and C. L. Mainardi. 1985. Biochemical and immunological characterization of the secreted forms of the human neutrophil gelatinase. J. Biol. Chem. 260:2493-2500.

15. Hibbs, M. S., J. R. Hoidal, and A. H. Kang. 1987. Expression of a metalloproteinase that degrades native type $\mathrm{V}$ collagen and denatured collagens by cultured human alveolar macrophages. J. Clin. Invest. 80:1644-1650.

16. Wilhelm, S. M., I. E. Collier, B. L. Marmer, A. Z. Eisen, G. A. Grant, G. I Goldberg. 1989. SV40-transformed human lung fibroblasts secrete a 92kDa type IV collagenase which is identical to that secreted by normal human macrophages. J. Biol. Chem. 264:17213-17321.

17. Dayer, J.-M., J. Bréard, L. Chess, and S. M. Krane. 1979. Participation of monocyte-macrophages and lymphocytes in the production of a factor that stimulates collagenase and prostaglandin release by rheumatoid synovial cells. J. Clin. Invest. 64:1386-1392.

18. Larrick, J. W., D. G. Fischer, S. J. Anderson, and H. S. Koren. 1980. Characterization of a human macrophagelike cell line stimulated in vitro: model of macrophage functions. J. Immunol. 125:6-12.

19. Auron, P. E., A. C. Webb, L. J. Rosenwasser, S. F. Mucci, A. Rich, S. M Wolff, and C. A. Dinarello. 1984. Nucleotide sequence of human monocytic interleukin-1 precursor cDNA. Proc. Natl. Acad. Sci. USA. 81:7907-7911.

20. Derynck, R., A. B. Roberts, M. E. Winkler, E. Y. Chen, and D. V. Goeddel. 1984. Human transforming growth factor-alpha: precursor structure and expression in E. coli. Cell. 38:287-297.

21. Derynck, R., J. A. Jarrett, E. Y. Chen, D. H. Eaton, J. R. Bell, R. K. Assoian, A. B. Roberts, M. B. Sporn, and D. V. Goeddel. 1985. Human transforming growth factor-beta cDNA sequence and expression in tumor lines. $\mathrm{Na}$ ture (Lond.). 316:701-705.

22. Pennica, D., G. E. Nedwin, J. S. Hayflick, P. H. Seeburg, R. Derynck M. A. Palladino, W. J. Kohr, B. B. Aggarwal, and D. V. Goeddel. 1984. Human tumor necrosis factor: precursor structure, expression, and homology to lymphotoxin. Nature (Lond.). 312:724-729.

23. Gray, P. W., B. B. Aggarwal, C. V. Benton, T. S. Bringman, W. J. Henzel, J. A. Jarrett, D. W. Leung, B. Moffat, P. Ng. L. P. Svedersky, M. A. Palladino, and G. E. Nedwin. 1984. Cloning and expression of cDNA for human lymphotoxin, lymphokine with tumor necrosis factor activity. Nature (Lond.). 312:721-724.

24. Gray, P. W., D. W. Leung, D. Pennica, E. Yelverton, R. Jajarian, C. C. Simonsen, R. Derynck, P. J. Sherwood, D. M. Wallace, S. L. Berger, A. D. Levinson, and D. V. Goeddel. 1982. Expression of human immune interferon cDNA in E. coli and monkey cells. Nature (Lond.). 295:503-508.

25. Unemori, E. N., and Z. Werb. 1988. Collagenase expression and endogenous activation in rabbit synovial fibroblasts stimulated by the calcium ionophore A23187. J. Biol. Chem. 263:16252-16259.

26. Herron, G. S., Z. Werb, K. Dwyer, and M. J. Banda. 1986. Secretion of metalloproteinases by stimulated capillary endothelial cells. I. Production of procollagenase and prostromelysin exceeds expression of proteolytic activity. J. Biol. Chem. 261:2810-2913.

27. Barrett, A. J. 1977. Use of inhibitors in the classification of endopeptidases. In Proteinases in Mammalian Cells and Tissues. A. J. Barrett, editor. North-Holland Publishing Co., Amsterdam. 15-18.

28. Towbin, H., T. Staehlin, and J. Gordon. 1979. Electrophoretic transfer of proteins from polyacrylamide gels to nitrocellulose sheets: procedure and some applications. Proc. Natl. Acad. Sci. USA. 76:4350-4354.
29. Werb, Z., and M. C. Burleigh. 1974. A specific collagenase from rabbit fibroblasts in monolayer cuture. Biochem. J. 137:373-385.

30. Cawston, T. E., and A. J. Barrett. 1979. A rapid and reproducible assay for collagenase using $\left[1-{ }^{14} \mathrm{C}\right]$ acetylated collagen. Anal. Biochem. 99:340-345.

31. Greenberg, M. E. 1987. Analysis of RNA by Northern hybridization. In Current Protocols in Molecular Biology. F. M. Ausubel, R. Brent, R. E. Kingston, D. D. Moore, J. A. Smith, J. G. Seidman, and K. Struhl, editors. John Wiley and Sons, Inc., New York. Sect. 4.9.1.

32. Collier, I. E., S. M. Wilhelm, A. Z. Eisen, B. L. Marmer, G. A. Grant, J. L. Seltzer, A. Kronberger, C. He, E. A. Bauer, and G. I. Goldberg. 1988. H-ras oncogene-transformed human bronchial epithelial cells (TBE-1) secrete a single metalloprotease capable of degrading basement membrane collagen. $\mathrm{J}$. Biol. Chem. 263:6579-6587.

33. Whitham, S. E., G. Murphy, P. Angel, H. J. Rahmsdorf, B. J. Smith, A. Lyons, T. J. R. Harris, J. J. Reynolds, and A. J. P. Docherty. 1986. Comparison of human stromelysin and collagenase by cloning and sequence analysis. Biochem. J. 240:913-916.

34. Wood, D. D., E. J. Ihrie, C. A. Dinarello, and P. L. Cohen. 1985. Release of interleukin-1 from human synovial tissue in vitro. Arthritis Rheum. 28:853862.

35. Wood, D. D., E. J. Ihrie, C. A. Dinarello, and P. L. Cohen. 1983. Isolation of an interleukin-1-like factor from human joint effusions. Arthritis Rheum. 26:975-983.

36. Saxne, T., M. A. Palladino, Jr., D. Heinegard, N. Talal, and F. A. Wollheim. 1988. Detection of tumor necrosis factor $\alpha$ but not tumor necrosis factor $\beta$ in rheumatoid arthritis synovial fluid and serum. Arthritis Rheum. 31:10411045.

37. Guerne, P.-A., B. L. Zuraw, J. H. Vaughan, D. A. Carson, and M. Lotz 1989. Synovium as a source of interleukin 6 in vitro. J. Clin. Invest. 83:585-592.

38. Fava, R., N. Olsen, J. Keski-Oja, H. Moses, and T. Pincus. 1989. Active and latent forms of transforming growth factor $\beta$ activity in synovial effusions. $J$. Exp. Med. 169:291-296.

39. Firestein, G. S., W. D. Xu, K. Townsend, D. Broide, J. Alvaro-Garcia, A. Glasebrook, and N. J. Zvaifler. 1988. Cytokines in chronic inflammatory arthritis. I. Failure to detect $T$ cell lymphokines (interleukin-2 and interleukin-3) and presence of macrophage colony-stimulating factor (CSF-1) and a novel mast cell growth factor in rheumatoid synovitis. J. Exp. Med. 168:1573-1586.

40. Mainardi, C. L., M. S. Hibbs, K. A. Hasty, and J. M. Seyer. 1984. Purification of a type $\mathrm{V}$ collagen degrading metalloproteinase from rabbit alveolar macrophages. Collagen Relat. Res. 4:479-492.

41. Amento, E. P., and M. U. Hayes. 1988. Lymphotoxin (tumor necrosis factor- $\beta$ ) induces and augments collagen, collagenase and prostaglandin E2 production by fibroblasts: potential role in inflammatory and fibrotic processes. Arthritis Rheum. 31(Suppl):S21. (Abstr.)

42. Amento, E. P. A. K. Bhan, K. G. McCullagh, and S. M. Krane. 1985. Influences of gamma interferon on synovial fibroblastlike cells. Ia. Induction and inhibition of collagen synthesis. J. Clin. Invest. 76:837-848.

43. Chua, C. C., D. E. Geiman, G. H. Keller, and R. L. Ladda. 1985. Induction of collagenase secretion in human fibroblast cultures by growth promoting factors. J. Biol. Chem. 260:5213-5216.

44. Krane, S. M., W. Conca, M. L. Stephenson, E. P. Amento, and M. B. Goldring. 1990. Mechanisms of matrix degradation in rheumatoid arthritis. Ann. N. Y. Acad. Sci. 580:340-354.

45. Mizel, S. B., J.-M. Dayer, S. M. Krane, and S. E. Mergenhagen. 1981. Stimulation of rheumatoid synovial cell collagenase and prostaglandin production by partially purified lymphocyte-activating factor (interleukin-1). Proc. Natl. Acad. Sci. USA. 78:2474-2477.

46. Postlethwaite, A. E., C. B. Lachman, and A. H. Kang. 1984. Induction of fibroblast proliferation by interleukin-1 derived from human monocytic leukemia cells. Arthritis Rheum. 27:995-1001.

47. Aggarwal, B. B., T. E. Eessalu, and P. E. Hass. 1985. Characterization of receptors for human tumor necrosis factor and their regulation by $\gamma$-interferon. Nature (Lond.). 318:665-667.

48. Firestein, G. S., J. M. Alvaro-Garcia, and R. Maki. 1990. Quantitative analysis of cytokine gene expression in rheumatoid arthritis. J. Immunol. 136:3347-3353. 